\title{
EFFECT OF CEREBELLUM RADIATION DOSIMETRY ON COGNITIVE OUTCOMES IN CHILDREN WITH INFRATENTORIAL EPENDYMOMA
}

\author{
Thomas E. Merchant, DO, PhD ${ }^{1}$, Shelly Sharma, MD1, Xiaoping Xiong, $\mathrm{PhD}^{2}$, Shengjie Wu, \\ MS $^{2}$, and Heather Conklin, PhD $^{3}$ \\ ${ }^{1}$ Division of Radiation Oncology, St. Jude Children's Research Hospital, Memphis, TN \\ 2Department of Biostatistics, St. Jude Children's Research Hospital, Memphis, TN \\ ${ }^{3}$ Department of Psychology, St. Jude Children's Research Hospital, Memphis, TN
}

\section{Abstract}

Background-Cognitive decline is a recognized effect of irradiation (RT) in children treated with brain tumor. The importance of the cerebellum and its contribution to cognition has been recognized; however, the effect of RT on cerebellar-linked neurocognitive deficits has yet to be explored.

Patients and Methods-Seventy-six children (39 males) with a median age of 3.3 years (1-17 years) were irradiated for infratentorial ependymoma from 1997 to 2008. The total prescribed dose was 54-59.4Gy administered to the post-operative tumor bed with $10 \mathrm{~mm}$ or $5 \mathrm{~mm}$ clinical target volume margin. Age-appropriate cognitive and academic testing was performed prior to the start of RT and then repeated at 6 months and annually through 5 years. The anterior and posterior cerebellum and other normal brain volumes were contoured on post contrast, T1-weighted postoperative magnetic resonance imaging registered to treatment planning computed tomography images. Mean doses were calculated and used with time after RT and other clinical covariates to model their effect on neurocognitive test scores.

Results-Considering only the statistically significant rates in longitudinal changes for test scores and models that included mean dose, there was a correlation between mean infratentorial dose and IQ (-0.190 pts/Gy/yr; $\mathrm{P}=0.001)$, math $(-0.164 \mathrm{pts} / \mathrm{Gy} / \mathrm{yr} ; \mathrm{P}=0.010)$, reading $(-0.137$ $\mathrm{pts} / \mathrm{Gy} / \mathrm{yr} ; \mathrm{P}=0.011)$ and spelling scores $(-0.147 \mathrm{pts} / \mathrm{Gy} / \mathrm{yr} ; \mathrm{P}=0.012)$, where $\mathrm{Gy}$ is measured for the difference between the RT mean dose received by individual patient against the mean of the patient group. There was a correlation between mean anterior cerebellum dose and IQ scores $(-0.116 \mathrm{pts} / \mathrm{Gy} / \mathrm{yr} ; \mathrm{P}=0.042)$ and mean posterior cerebellum dose and IQ $(-0.150 \mathrm{pts} / \mathrm{Gy} / \mathrm{yr}$; $\mathrm{P}=0.002)$, math $(-0.120 \mathrm{pts} / \mathrm{Gy} / \mathrm{yr} ; \mathrm{P}=0.023)$, reading $(-0.111 \mathrm{pts} / \mathrm{Gy} / \mathrm{yr} ; \mathrm{P}=0.012)$, and spelling scores $(-0.117 \mathrm{pts} / \mathrm{Gy} / \mathrm{yr} ; \mathrm{P}=0.015)$.

Corresponding Author: Thomas E. Merchant, DO, PhD, Division of Radiation Oncology, St. Jude Children's Research Hospital, 262 Danny Thomas Place, Memphis, TN 38105-3678, Telephone: (901) 595-3604, Fax: (901) 595-3113, thomas.merchant@ stjude.org. 
Conclusion-Sparing portions of the cerebellum should be considered in RT planning for children with infratentorial ependymoma because of the potential impact of radiation dose on cognitive function.

\section{Introduction}

Neurocognitive impairment after irradiation is a major concern when treating children with brain tumors, especially those who share the prospect for long-term survival. Measures to reduce radiation dose to the normal brain have been successful to the extent that even very young children with localized brain tumors are offered irradiation as a part of initial management in clinical trials (ACNS0121 [NCT00027846], ACNS0831 [NCT01096368] and A9934 [1]).

Reducing radiation dose to normal brain has been achieved through target volume reduction and by reducing the total prescribed dose. Newer methods of irradiation have been investigated including conformal and intensity-modulated photon and proton therapy. These methods rely on a detailed understanding of radiation dose-volume effects which link the incidence and severity of neurocognitive impairment to specific volumes of normal brain defined by their function.

Our team was among the first to describe the association between radiation dose distributions and longitudinal cognitive measures in low-grade glioma [2], medulloblastoma [3], ependymoma [4] and craniopharyngioma [5]. Children with ependymoma show remarkable resiliency and preservation of cognition as determined by longitudinal measures of intelligence, memory, attention and behavior [6-8].

Possible explanations for preservation of cognition include the resiliency of the cerebellum or its contribution to cognitive processes. Cognition in humans has been thought to involve frontal and tempo-parietal lobes, the hippocampus-mammillary complex and other supratentorial regions. There is increasing evidence to suggest a role for the cerebellum in complex cognitive operations like language function, working memory, executive function and emotion [9-11]. Investigations suggest the posterior cerebellum has a role in cognition and the anterior cerebellum appears to contribute to sensorimotor function [10;12]. Cognitive deficits in children with cerebellar tumors treated with surgery alone have been reported [13-19]. It remains unclear whether cerebellar irradiation affects cognitive function.

The impact of irradiation on the cerebellum has become relevant in the current era as the posterior fossa has become one of the most commonly irradiated sites. Understanding the effect of radiation dose will improve our ability to selectively spare the cerebellum in the process of treatment planning and help us to further understand the neurobiological mechanisms underlying cognitive deficits.

We investigated the association between radiation dose to the cerebellum and the time course of cognitive change after irradiation. Children enrolled on our prospective trials using radiation therapy for infratentorial ependymoma provide a group from which prospective 
neurocognitive assessments have been performed and a unique opportunity to explore the correlation between cerebellar irradiation and cognition.

\section{Methods and Materials}

\section{Patients}

Seventy-six pediatric patients (39 males), median age 3.3 years (range; $1-17$ years) diagnosed with localized infratentorial ependymoma and enrolled in a Phase II trial of conformal radiation therapy (CRT) between 1997 and 2008 were included. Patients included in this investigation had a minimum of two neurocognitive assessments. The details of the trial and results were reported earlier [20]. None of the participants had tumor recurrence prior to the neurocognitive assessments and none were censored because of a decline in function. Institutional Review Board (IRB) approval was obtained and data was managed according to the Health Insurance Portability and Accountability Act of 1996 (HIPAA). Written, informed consent was required.

\section{Radiation treatment planning, cerebellar contouring and radiation dose}

All patients received conformal or intensity-modulated radiation therapy using conventional fractionation of $1.8 \mathrm{~Gy}$ per day. The total dose was 54 or $59.4 \mathrm{~Gy}$ administered 5 days per week. The lower dose was used for children under the age of 18 months treated with grosstotal resection. The gross tumor volume included the post-operative tumor bed and residual disease. The clinical target volume (CTV) margin (10 $\mathrm{mm}$ or $5 \mathrm{~mm}$ ) surrounded the gross tumor volume to account for subclinical tumor extension. This volume was confined at nonneural interfaces. The CTV was surrounded geometrically by the planning target volume (PTV) margin (3-5mm) to account for variability in positioning. Treatment was prescribed such that $100 \%$ of the PTV received at least $95 \%$ of the protocol specified dose.

The supratentorial and infratentorial brain, anterior and posterior cerebellar lobes were contoured on post-operative T1-weighted magnetic resonance images (3D-acquired MP RAGE post-contrast with in-plane resolution of $1 \mathrm{~mm}$ ) obtained immediately prior to radiation therapy and co-registered to the computed tomography dataset used for dose calculation (Fig. 1). The infratentorial brain included the entire brainstem and cerebellum. The cerebellum was segmented into anterior and posterior lobes according to the magnetic resonance imaging based atlas outlined by Schmahmann et al [21]. The primary fissure was identified in the mid-sagittal plane and was used as a landmark for segmenting the anterior and posterior cerebellar lobes. Lobules I to $\mathrm{V}$ were included in anterior cerebellar lobes and lobules VI to $\mathrm{X}$ were included in posterior cerebellar lobes. Differential dose volume histograms were calculated for the normal tissue volumes. For purposes of analysis, the left and right cerebellar lobes were combined because it was assumed that irradiation of the other lobe would have a similar effect and taken as the error term in the model and reduce the power of the statistical test. The mean doses were highly correlated between the anterior cerebellum left 5679.6 $\pm 479.8 \mathrm{cGy}$ and right $5676.9 \pm 411.6 \mathrm{cGy}$ and the posterior cerebellum left 5060.7 $\pm 582.9 \mathrm{cGy}$ and right $5030.8 \pm 635.3 \mathrm{cGy}$. 


\section{Surgery and chemotherapy}

All patients underwent resection prior to radiation therapy. Ventriculoperitoneal cerebrospinal fluid (CSF) shunting was performed as required in 24 patients. Twelve patients received chemotherapy prior to irradiation using cyclophosphamide and cisplatin or carboplatin, etoposide, and vincristine.

\section{Cognitive outcomes (Intelligence quotient [IQ], Academic tests, Visual-Auditory Learning [VAL] scores)}

Patients underwent age appropriate prospective neurocognitive assessment at the outset of treatment, after the initial surgery and usually prior to irradiation but otherwise within 3 months, 6 months and annually through 5 years. IQ was measured using the mental index of Bayley Scales or derived from the Information, Similarities and Block Design subtests from the age-appropriate Wechsler scale [22;23]. Academic testing included three subsets from Wechsler Individual Achievement Test viz. WIAT Word Reading, Spelling and Math Reasoning [24]. Visual learning was assessed with the Visual-Auditory Learning Test (VAL) from Woodcock-Johnson Tests of Cognitive Ability: Revised [25]. The VAL test is an associative learning task of word-symbol pairings. Each subset score was converted to age standardized score based on a large, representative, normative sample with mean of 100 and standard deviation of 15 .

\section{Statistical analysis}

A mixed-effects model with random coefficients for intercept and slope was used for the analysis. The intercept was the estimate of the baseline scores; the slope was the rate of change for the population average scores on the specific neurocognitive test and measured the magnitude of the effect of the independent variable. The p-value of the coefficient was considered for comparative significance relative to the mean for the patient group. Longitudinal trends of population average scores were first estimated with time as the only covariate. The following covariates were then used in the multivariate analysis: age at the time of irradiation based on the mean of 4.8 years (younger $<4.8$ years; older $>4.8$ years), sex, race, presence of a CSF shunt, the use of pre-irradiation chemotherapy, gross tumor volume and clinical and planning target volumes, and mean dose to the supratentorial brain, infratentorial brain, anterior cerebellum and posterior cerebellum and left and right hippocampi. To analyze the effect of radiation dose, the difference in the mean dose from the population average was used as a covariate. The number of tests contributing to the analysis included IQ $(n=559)$, WIAT Math scores $(n=365)$, WIAT Reading scores $(n=363)$, WIAT Spelling scores $(\mathrm{n}=361)$, and VAL $(\mathrm{n}=292)$. Differences in the number of evaluations were attributed to age at the time of testing and the appropriateness of the measure. All analyses were performed using SAS version 9.2 (Cary, NC).

\section{Results}

The mean dose $( \pm$ SE) to the supratentorial brain $(14.04 \pm 3.24 \mathrm{~Gy})$, infratentorial brain $(52.13 \pm 4.50 \mathrm{~Gy})$, anterior cerebellum $(56.78 \pm 4.32 \mathrm{~Gy})$ and posterior cerebellum (50.6 \pm $5.82 \mathrm{~Gy})$ were calculated. Baseline mean neurocognitive scores were within the normal range (mean \pm SE) for WIAT reading $(103.60 \pm 1.53)$, WIAT math $(98.62 \pm 1.93)$, WIAT spelling 
$(102.30 \pm 2.21)$, VAL $(94.66 \pm 2.54)$ and IQ which was below average $(96.59 \pm 1.78)$. Based on longitudinal observations through the first 5 years after irradiation, improvement was observed in IQ and VAL scores at the rate of $0.1803 \pm 0.246$ points/year $(\mathrm{P}=0.467)$ and $1.361 \pm 0.371$ points/year $(\mathrm{P}=<.001)$, respectively. Among the academic achievement scores, WIAT math scores remained unchanged over time whereas a modest but statistically significant decline was observed in WIAT reading scores at the rate of $-0.96 \pm 0.24$ points/ year $(\mathrm{P}=<0.001)$ and in WIAT spelling scores of $-0.85 \pm 0.35$ points/year $(\mathrm{P}=0.019)$. (Table 1)

The association between clinical variables and baseline cognitive scores was investigated. There was a negative correlation between baseline scores and the presence of a CSF shunt for all of the cognitive measures. This correlation was statistically significant for IQ $(-11.55, \mathrm{P}=0.002)$, WIAT reading $(-8.17, \mathrm{P}=0.003)$, WIAT math $(-7.15, \mathrm{P}=0.036)$, WIAT spelling $(-6.08, \mathrm{P}=0.057)$ and VAL $(-9.05, \mathrm{P}=<0.037)$. There was a positive correlation with age at the time of irradiation and baseline IQ scores $\left(1.31\right.$ pts $\left./ \mathrm{yad}^{1}, \mathrm{P}=0.006\right)$ and VAL scores (2.24 pts/yad, $\mathrm{P}=<0.001)$ and negative correlation between age and baseline WIAT reading scores $(-0.91 / \mathrm{yad}, \mathrm{P}=<0.001)$. The use of pre-irradiation chemotherapy had no impact on baseline scores. None of the clinical variables of age at irradiation, CSF shunt or pre-irradiation chemotherapy impacted longitudinal change in neurocognitive scores.

\section{Effect of Cerebellar Dosimetry on longitudinal IQ scores}

When IQ scores were estimated using mixed model equation adjusted for time since irradiation, there was a significant association between IQ scores and infratentorial, anterior cerebellar, or posterior cerebellar mean dose and time after treatment. The magnitude of the effect ranged from $-0.150 \mathrm{pts} / \mathrm{Gy} / \mathrm{yr}$ for the posterior cerebellum to $-0.190 \mathrm{pts} / \mathrm{Gy} / \mathrm{yr}$ for the infratentorial brain.

\section{Effect of Cerebellar Dosimetry on longitudinal WIAT Reading, Math and Spelling scores}

When WIAT Reading, Math and Spelling scores were estimated individually using mixed model equations, adjusted for time since irradiation, infratentorial and posterior cerebellar mean doses were found to have significant negative effect on longitudinal trend of all WIAT academic scores ranging from $-0.111 \mathrm{pts} / \mathrm{Gy} / \mathrm{yr}$ for the posterior cerebellum on WIAT reading scores to $-0.164 \mathrm{pts} / \mathrm{Gy} / \mathrm{yr}$ for the infratentorial brain on WIAT math scores. (Table 2)

\section{Effect of Tumor Volume, Surgery and Radiation Therapy Parameters}

There was an association between the gross tumor volume and the longitudinal VAL scores. The magnitude of the effect was $-0.0729 \mathrm{pts} / \mathrm{mL} / \mathrm{yr}(\mathrm{P}=0.0222)$. There was no association between number of surgery procedures or pre-irradiation extent of resection and longitudinal scores. Fifty-one patients had one surgery, 21 had two operations and 4 underwent 4 attempts at resection prior to irradiation. The pre-operative extent of resection was GTR in 61, NTR in 11 and STR in 4. There was an association between mean dose to the left hippocampus and longitudinal IQ (-0.0558 pts/Gy/yr; P=0.0305) and VAL (-0.0517

\footnotetext{
$1_{\text {yad }}($ year-age-difference $)=$ difference between the age of the individual patient and group mean
} 
$\mathrm{pts} / \mathrm{Gy} / \mathrm{yr} ; \mathrm{P}=0.0063$ ) scores. There was an association between mean dose to the right hippocampus and VAL ( $-0.0683 \mathrm{pts} / \mathrm{Gy} / \mathrm{yr} ; \mathrm{P}=0.0024)$ scores. There was no association between cumulative total dose (54Gy vs. 59.4Gy) and longitudinal cognitive scores. Eight patients received 54Gy and the remainder 59.4Gy.

\section{Discussion}

Ependymoma is the third most common brain tumor in children and overall survival rates exceed $70 \%$ when measured at 5 years in patients receiving immediate post-operative irradiation [20]. Most children with ependymoma have infratentorial tumor location and excellent functional outcomes after standard treatment; however, among those who experience cognitive decline, younger age at the time of irradiation, multiple and extensive surgery, hydrocephalus, and chemotherapy have been implicated in addition to dose and volume of irradiation [6;26-32]. Although our analysis identified factors associated with cognitive decline, the associated risk was small. This study is a step forward in our understanding about the effects of irradiation in a functional sub-volume of the normal brain with results that associate cerebellar irradiation with specific cognitive effects in children with ependymoma. High-dose irradiation of the infratentorial brain was associated with a steeper decline in multiple cognitive domains. The negative effect on IQ was contributed by both anterior and posterior cerebellar mean doses; whereas, the decline in academic achievement scores was primarily attributed to the mean posterior cerebellar doses. These results suggest that sparing of the cerebellar volume should be considered during radiation planning and that smaller target volumes should be considered when feasible.

The cerebellum has been thought to be involved in regulation of motor coordination, balance and motor speech [9;33;34]. In the past two decades, neuroanatomical studies have shown reciprocal connectivity of cerebellum with cerebral frontal, parietal and temporal associative areas involved in higher cognitive functioning [9;12]. Numerous functional neuroimaging studies showed activation of cerebellum during cognitive tasks like language, executive function and working memory [9;12]. As per functional dichotomy of cerebellum [12;33]; anterior cerebellum having reciprocal connection to cerebral motor cortex and spinal cord is thought to be involved in sensorimotor functions and posterior lobe, defined as the region posterior and inferior to primary fissure and comprising lobule VI to X, to be involved in cognitive domains [11;33]. The association of higher than population average posterior cerebellar doses with declines in the cognitive outcomes viz. IQ, reading, math and spelling scores, replicate this functional topography to some extent. Negative effect of anterior cerebellar mean doses with estimated IQ may reflect the effect of anterior cerebellar irradiation on the timed motor component of this assessment (e.g., while performing the block design subset child is required to place the blocks as per a specific design within a limited time period thus relying on a child's motor abilities speed).

Contrary to the studies evaluating cognitive outcomes in children receiving whole brain irradiation $[26 ; 35 ; 36]$ and consistent with reports on children treated with limited irradiation [4;26;31], average IQ scores of our cohort after 5 years of CRT falls within the range of population norms. IQ is a complex cognitive construct that involves anatomically distributed regions of the brain including a variety of supratentorial and infratentorial brain sub volumes 
like frontal, parietal gray matter volume and, putamen and the entire cerebellar volume [37]. While a recent study of children treated for ependymoma with proton radiotherapy fails to indicate a decline in intellectual or adaptive functioning, the sample size is small ( $\mathrm{n}=14$ and 28 , respectively) and the follow-up time short (average of 2 years), precluding conclusion or comparison with current findings [38]. Although we are not clear at this point of relative contributions of different brain regions involved in this complex cognitive ability, the sparing effect of newer methods on IQ or greater IQ decline observed in those treated by cranial irradiation [26], can be hypothesized to be secondary to the additive effects of tumor and other treatments most notably surgery to the functional subunits that may be distant but anatomically connected through white matter bundles. This is supported by the fact that global white matter changes reflecting demyelination and thus disrupting trans-synaptic communications have been implicated as a possible mechanism underlying post-irradiation brain injury causing cognitive deficits [39;40]. Similarly, a diffusion tensor imaging based study in children with posterior fossa tumors revealed that disruption of cerebello-thalamocerebral pathways following irradiation were associated with poorer working memory, a core cognitive skill involved in complex cognitive functions including IQ and academics [41]. The same authors stated that diffuse white matter changes in the posterior fossa following irradiation and disruption of multiple other pathways connecting cerebellum to supratentorial structures may have been responsible for deficits.

Linguistic skills viz. reading and spelling were more vulnerable than math in our cohort as depicted by the decline in these group mean scores over time. This finding is contrary to the greater math impairment observed in children treated with cranial irradiation [42] but may reflect greater specificity of localized cerebellar insult following irradiation [43]. The frontal, parietal, temporal, and occipital regions have been reported to be activated in response to tasks eluding orthographic, phonological, and semantic processes involved in reading [44]. The posterior cerebellar regions have now been added to this list [44;45]. Cerebellar hemispheric regions adjacent to posterior superior fissure are bilaterally being activated during phonological assembly and deep nuclear regions on the right activated during semantic processing [44]. Riva et al [46] in their study on children with cerebellar tumors reported poor naming and comprehension abilities which were more pronounced in right cerebellar lesions. The majority of our patients had midline tumors. Minimal dose differences in right and left cerebellar hemispheres limited our ability to test this lateralization effect [6].

Cerebellar involvement in mathematical calculations has been documented and is thought to rely on its connectivity with frontal brain regions [47]. WIAT math mean scores on follow up though were unchanged as reported earlier [6] but children receiving higher than average population mean doses to infratentorial brain and more specifically to posterior cerebellum had steeper declines in all three academic achievement scores over time showing a deleterious effect of higher cerebellar doses on these skills.

Amongst the various clinical covariates studied, younger children had lower baseline IQ scores but age effect was not evident at 5 years after CRT, which could be attributed to the sparing effect of conformal irradiation that probably doesn't halt their recovery from perioperative insults [6;26;29]. Consistent with earlier reports, the deleterious negative 
association of severe hydrocephalus on cognition was evident and the reversible nature of this effect was replicated by the loss of this negative association with the longitudinal trends [29]. IQ scores are age standardized to account for change in performance associated with typical development. The positive correlation between age at time of irradiation and baseline IQ scores likely reflects the protective effect of age with respect to potential insults encountered prior to irradiation (e.g., surgical interventions, chemotherapy).

Though mean supratentorial doses were not found to affect any longitudinal cognitive trend in this analysis, we cannot outwardly refute this aspect as cranial doses as low as 18Gy have been implicated to effect cognition in children with acute lymphoid leukemia [48] and mean supratentorial dose for our cohort was around 14Gy. Our previous analysis revealed that supratentorial volumes receiving doses as low as $0-5$ Gy have negative effect on IQ [4]. This difference could have been because of the different parameter used in present analysis i.e., mean dose as opposed to the volume receiving dose between 0 and 5Gy[4]. Long term detrimental effects of surgery cannot be completely excluded. Associations of long term cognitive deficits with post-operative acute cerebellar insults like cerebellar mutism have been suggested in literature [13;16;31]. We realize that the academic performances assessed are known to be influenced by other behavioral and environmental factors such as prolonged school absences which could not be accounted for but would not be expected to affect academic domains differentially.

In this relatively homogenous cohort we were able to demonstrate that high dose cerebellar irradiation negatively influenced the longitudinal trend of multiple cognitive measures and mirrored the functional topography of cerebellum. Our goal was not to prove whether the cerebellum was directly involved in cognition but rather to determine the contribution of cerebellar irradiation on long-term cognitive effects realizing that the cerebellum is part of a neural network.

\section{Supplementary Material}

Refer to Web version on PubMed Central for supplementary material.

\section{Acknowledgments}

Research Support: Supported in part by the National Cancer Institute Cancer Center Support Grant No. CA21765, the American Cancer Society Research Project Grant No. RPG-99-252-01-CCE, and the American Lebanese Syrian and Associated Charities (ALSAC).

\section{Reference List}

1. Ashley DM, Merchant TE, Strother D, Zhou T, Duffner P, Burger PC, et al. Induction chemotherapy and conformal radiation therapy for very young children with nonmetastatic medulloblastoma: Children's Oncology Group study P9934. J Clin Oncol. 2012; 30(26):3181-3186. [PubMed: 22851568]

2. Merchant TE, Conklin HM, Wu S, Lustig RH, Xiong X. Late effects of conformal radiation therapy for pediatric patients with low-grade glioma: prospective evaluation of cognitive, endocrine, and hearing deficits. J Clin Oncol. 2009; 27(22):3691-3697. [PubMed: 19581535] 
3. Merchant TE, Kiehna EN, Li C, Shukla H, Sengupta S, Xiong X, et al. Modeling radiation dosimetry to predict cognitive outcomes in pediatric patients with CNS embryonal tumors including medulloblastoma. Int J Radiat Oncol Biol Phys. 2006; 65(1):210-221. [PubMed: 16472938]

4. Merchant TE, Kiehna EN, Li C, Xiong X, Mulhern RK. Radiation dosimetry predicts IQ after conformal radiation therapy in pediatric patients with localized ependymoma. Int J Radiat Oncol Biol Phys. 2005; 63(5):1546-1554. [PubMed: 16115736]

5. Merchant TE, Kiehna EN, Kun LE, Mulhern RK, Li C, Xiong X, et al. Phase II trial of conformal radiation therapy for pediatric patients with craniopharyngioma and correlation of surgical factors and radiation dosimetry with change in cognitive function. J Neurosurg. 2006; 104(2 Suppl):94102. [PubMed: 16506496]

6. Conklin HM, Li C, Xiong X, Ogg RJ, Merchant TE. Predicting change in academic abilities after conformal radiation therapy for localized ependymoma. J Clin Oncol. 2008; 26(24):3965-3970. [PubMed: 18711186]

7. Di Pinto M, Conklin HM, Li C, Xiong X, Merchant TE. Investigating verbal and visual auditory learning after conformal radiation therapy for childhood ependymoma. Int J Radiat Oncol Biol Phys. 2010; 77(4):1002-1008. [PubMed: 19783376]

8. Kiehna EN, Mulhern RK, Li C, Xiong X, Merchant TE. Changes in attentional performance of children and young adults with localized primary brain tumors after conformal radiation therapy. $\mathrm{J}$ Clin Oncol. 2006; 24(33):5283-5290. [PubMed: 17114662]

9. Baillieux H, De Smet HJ, Paquier PF, De Deyn PP, Marien P. Cerebellar neurocognition: insights into the bottom of the brain. Clin Neurol Neurosurg. 2008; 110(8):763-773. [PubMed: 18602745]

10. Grimaldi G, Manto M. Topography of cerebellar deficits in humans. Cerebellum. 2012; 11(2):336351. [PubMed: 21240580]

11. Schmahmann JD. The role of the cerebellum in cognition and emotion: personal reflections since 1982 on the dysmetria of thought hypothesis, and its historical evolution from theory to therapy. Neuropsychol Rev. 2010; 20(3):236-260. [PubMed: 20821056]

12. Stoodley CJ. The cerebellum and cognition: evidence from functional imaging studies. Cerebellum. 2012; 11(2):352-365. [PubMed: 21373864]

13. Beebe DW, Ris MD, Armstrong FD, Fontanesi J, Mulhern R, Holmes E, et al. Cognitive and adaptive outcome in low-grade pediatric cerebellar astrocytomas: evidence of diminished cognitive and adaptive functioning in National Collaborative Research Studies (CCG 9891/POG 9130). J Clin Oncol. 2005; 23(22):5198-5204. [PubMed: 16051961]

14. Di RC, Chieffo D, Pettorini BL, Massimi L, Caldarelli M, Tamburrini G. Preoperative and postoperative neurological, neuropsychological and behavioral impairment in children with posterior cranial fossa astrocytomas and medulloblastomas: the role of the tumor and the impact of the surgical treatment. Childs Nerv Syst. 2010; 26(9):1173-1188. [PubMed: 20552208]

15. Levisohn L, Cronin-Golomb A, Schmahmann JD. Neuropsychological consequences of cerebellar tumour resection in children: cerebellar cognitive affective syndrome in a paediatric population. Brain. 2000; 123(Pt 5):1041-1050. [PubMed: 10775548]

16. Palmer SL, Hassall T, Evankovich K, Mabbott DJ, Bonner M, Deluca C, et al. Neurocognitive outcome 12 months following cerebellar mutism syndrome in pediatric patients with medulloblastoma. Neuro Oncol. 2010; 12(12):1311-1317. [PubMed: 20713408]

17. Schmahmann JD, Sherman JC. The cerebellar cognitive affective syndrome. Brain. 1998; 121(Pt 4):561-579. [PubMed: 9577385]

18. Stoodley CJ, Schmahmann JD. Evidence for topographic organization in the cerebellum of motor control versus cognitive and affective processing. Cortex. 2010; 46(7):831-844. [PubMed: 20152963]

19. Wells EM, Walsh KS, Khademian ZP, Keating RF, Packer RJ. The cerebellar mutism syndrome and its relation to cerebellar cognitive function and the cerebellar cognitive affective disorder. Dev Disabil Res Rev. 2008; 14(3):221-228. [PubMed: 18924161]

20. Merchant TE, Li C, Xiong X, Kun LE, Boop FA, Sanford RA. Conformal radiotherapy after surgery for paediatric ependymoma: a prospective study. Lancet Oncol. 2009; 10(3):258-266. [PubMed: 19274783] 
21. Schmahmann JD, Doyon J, McDonald D, Holmes C, Lavoie K, Hurwitz AS, et al. Threedimensional MRI atlas of the human cerebellum in proportional stereotaxic space. Neuroimage. 1999; 10(3 Pt 1):233-260. [PubMed: 10458940]

22. Wechsler, D. Wechsler Adult Intelligence Scale. New York, NY: The Psychological Corporation; 1981. Revised

23. Wechsler, D. Wechsler Intelligence Scale for Children. 3. New York, NY: The Psychological Corporation; 1991.

24. Wechsler, D. Wechsler Individual Achievement Test. New York, NY: The Psychological Corporation; 1992.

25. Woodcock, RW.; Johnson, MB. Woodcock-Johnson tests of cognitivie ability - Revised. New York, NY: Riverside Publishing Co; 1989.

26. Grill J, Renaux VK, Bulteau C, Viguier D, Levy-Piebois C, Sainte-Rose C, et al. Long-term intellectual outcome in children with posterior fossa tumors according to radiation doses and volumes. Int J Radiat Oncol Biol Phys. 1999; 45(1):137-145. [PubMed: 10477017]

27. Mabbott DJ, Spiegler BJ, Greenberg ML, Rutka JT, Hyder DJ, Bouffet E. Serial evaluation of academic and behavioral outcome after treatment with cranial radiation in childhood. J Clin Oncol. 2005; 23(10):2256-2263. [PubMed: 15800316]

28. Mabbott DJ, Penkman L, Witol A, Strother D, Bouffet E. Core neurocognitive functions in children treated for posterior fossa tumors. Neuropsychology. 2008; 22(2):159-168. [PubMed: 18331158]

29. Merchant TE, Mulhern RK, Krasin MJ, Kun LE, Williams T, Li C, et al. Preliminary results from a phase II trial of conformal radiation therapy and evaluation of radiation-related CNS effects for pediatric patients with localized ependymoma. J Clin Oncol. 2004; 22(15):3156-3162. [PubMed: 15284268]

30. Patel SK, Mullins WA, O'Neil SH, Wilson K. Neuropsychological differences between survivors of supratentorial and infratentorial brain tumours. J Intellect Disabil Res. 2011; 55(1):30-40. [PubMed: 21121992]

31. von HK, Kieffer V, Habrand JL, Kalifa C, Dellatolas G, Grill J. Impairment of intellectual functions after surgery and posterior fossa irradiation in children with ependymoma is related to age and neurologic complications. BMC Cancer. 2008; 8:15. [PubMed: 18208613]

32. Stoodley CJ, Schmahmann JD. Functional topography in the human cerebellum: a meta-analysis of neuroimaging studies. Neuroimage. 2009; 44(2):489-501. [PubMed: 18835452]

33. Timmann D, Daum I. Cerebellar contributions to cognitive functions: a progress report after two decades of research. Cerebellum. 2007; 6(3):159-162. [PubMed: 17786810]

34. Fuss M, Poljanc K, Hug EB. Full Scale IQ (FSIQ) changes in children treated with whole brain and partial brain irradiation. A review and analysis. Strahlenther Onkol. 2000; 176(12):573-581. [PubMed: 11140152]

35. Mulhern RK, Merchant TE, Gajjar A, Reddick WE, Kun LE. Late neurocognitive sequelae in survivors of brain tumours in childhood. Lancet Oncol. 2004; 5(7):399-408. [PubMed: 15231246]

36. Pangelinan MM, Zhang G, VanMeter JW, Clark JE, Hatfield BD, Haufler AJ. Beyond age and gender: relationships between cortical and subcortical brain volume and cognitive-motor abilities in school-age children. Neuroimage. 2011; 54(4):3093-3100. [PubMed: 21078402]

37. Reddick WE, Glass JO, Palmer SL, Wu S, Gajjar A, Langston JW, et al. Atypical white matter volume development in children following craniospinal irradiation. Neuro Oncol. 2005; 7(1):1219. [PubMed: 15701278]

38. Steen RG, Koury BSM, Granja CI, Xiong X, Wu S, Glass JO, et al. Effect of ionizing radiation on the human brain: white matter and gray matter T1 in pediatric brain tumor patients treated with conformal radiation therapy. Int J Radiat Oncol Biol Phys. 2001; 49(1):79-91. [PubMed: 11163500]

39. Law N, Bouffet E, Laughlin S, Laperriere N, Briere ME, Strother D, et al. Cerebello-thalamocerebral connections in pediatric brain tumor patients: impact on working memory. Neuroimage. 2011; 56(4):2238-2248. [PubMed: 21473922] 
40. Seaver E, Geyer R, Sulzbacher S, Warner M, Batzel L, Milstein J, et al. Psychosocial adjustment in long-term survivors of childhood medulloblastoma and ependymoma treated with craniospinal irradiation. Pediatr Neurosurg. 1994; 20(4):248-253. [PubMed: 8043463]

41. Baillieux H, De Smet HJ, Dobbeleir A, Paquier PF, De Deyn PP, Marien P. Cognitive and affective disturbances following focal cerebellar damage in adults: a neuropsychological and SPECT study. Cortex. 2010; 46(7):869-879. [PubMed: 19853848]

42. Philipose LE, Gottesman RF, Newhart M, Kleinman JT, Herskovits EH, Pawlak MA, et al. Neural regions essential for reading and spelling of words and pseudowords. Ann Neurol. 2007; 62(5): 481-492. [PubMed: 17702036]

43. Stoodley CJ, Valera EM, Schmahmann JD. Functional topography of the cerebellum for motor and cognitive tasks: an fMRI study. Neuroimage. 2012; 59(2):1560-1570. [PubMed: 21907811]

44. Riva D, Giorgi C. The cerebellum contributes to higher functions during development: evidence from a series of children surgically treated for posterior fossa tumours. Brain. 2000; 123(Pt 5): 1051-1061. [PubMed: 10775549]

45. Feng S, Fan Y, Yu Q, Lu Q, Tang YY. The cerebellum connectivity in mathematics cognition. BMC Neuroscience. 9(Supplement I):P155, 7-11, 2008.

46. Edelstein K, Spiegler BJ, Fung S, Panzarella T, Mabbott DJ, Jewitt N, et al. Early aging in adult survivors of childhood medulloblastoma: long-term neurocognitive, functional, and physical outcomes. Neuro Oncol. 2011; 13(5):536-545. [PubMed: 21367970] 


\section{Summary}

This study associates longitudinal deficits in IQ and academic achievement with collateral irradiation of the posterior cerebellum in children with infratentorial ependymoma. To further reduce cerebellar-linked neurocognitive deficits, radiation dose to the posterior cerebellum should be avoided in treatment planning and delivery. Advanced methods of radiation therapy may be used to further optimize the treatment of these patients. 


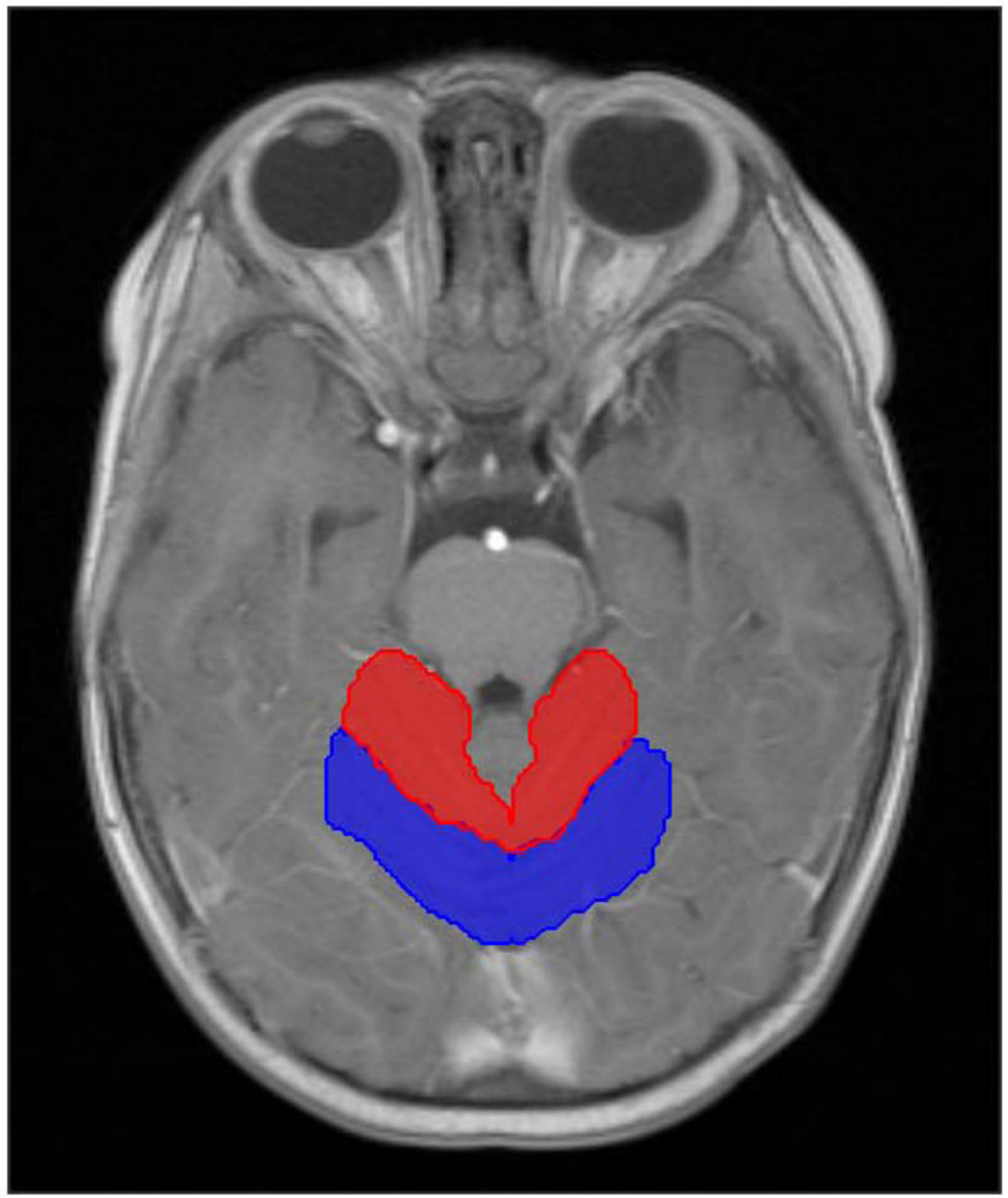

Fig. 1.

Axial post contrast T1-weighted MR image showing representative anterior (red) and posterior (blue) cerebellar contours. 


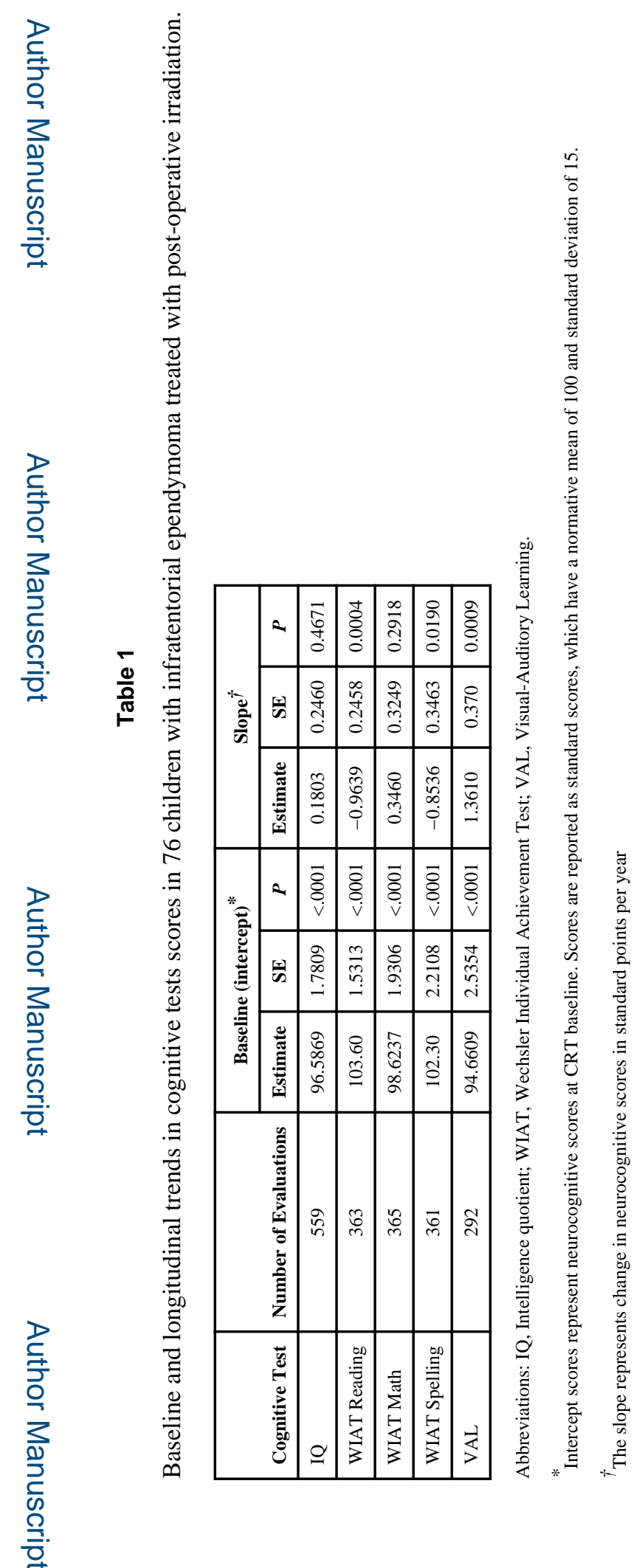

Int J Radiat Oncol Biol Phys. Author manuscript; available in PMC 2016 January 08. 


\section{Table 2}

The longitudinal effect of mean radiation dose on cognitive test scores in 76 children with infratentorial ependymoma.

\begin{tabular}{|c|c|c|c|}
\hline Brain Sub volume & Estimate $^{*}$ & Slope $^{\dagger} \mathbf{S E}$ & $p$ value \\
\hline \multicolumn{4}{|l|}{ IQ } \\
\hline Infratentorial Brain & -0.190 & 0.055 & 0.001 \\
\hline Anterior Cerebellum & -0.116 & 0.055 & 0.042 \\
\hline Posterior Cerebellum & -0.150 & 0.047 & 0.002 \\
\hline Supratentorial Brain & 0.057 & 0.076 & 0.451 \\
\hline \multicolumn{4}{|l|}{ WIAT Reading } \\
\hline Infratentorial Brain & -0.137 & 0.052 & 0.011 \\
\hline Anterior Cerebellum & -0.073 & 0.048 & 0.134 \\
\hline Posterior Cerebellum & -0.111 & 0.043 & 0.012 \\
\hline Supratentorial Brain & 0.039 & 0.066 & 0.557 \\
\hline \multicolumn{4}{|l|}{ WIAT Math } \\
\hline Infratentorial Brain & -0.164 & 0.062 & 0.010 \\
\hline Anterior Cerebellum & -0.056 & 0.062 & 0.368 \\
\hline Posterior Cerebellum & -0.120 & 0.052 & 0.023 \\
\hline Supratentorial Brain & 0.053 & 0.083 & 0.528 \\
\hline \multicolumn{4}{|l|}{ WIAT Spelling } \\
\hline Infratentorial Brain & -0.147 & 0.057 & 0.012 \\
\hline Anterior Cerebellum & -0.028 & 0.054 & 0.608 \\
\hline Posterior Cerebellum & -0.117 & 0.047 & 0.015 \\
\hline Supratentorial Brain & 0.021 & 0.073 & 0.779 \\
\hline \multicolumn{4}{|l|}{ VAL } \\
\hline Infratentorial Brain & -0.148 & 0.070 & 0.040 \\
\hline Anterior Cerebellum & 0.061 & 0.062 & 0.338 \\
\hline Posterior Cerebellum & -0.136 & 0.059 & 0.026 \\
\hline Supratentorial Brain & -0.050 & 0.090 & 0.585 \\
\hline
\end{tabular}

Abbreviations: IQ, Intelligence quotient; SE, standard error; NS, not significant; WIAT, Wechsler Individual Achievement Test; VAL, VisualAuditory Learning.

${ }^{\dagger}$ The slope represents rate of change in neurocognitive scores in standard points per year

* The Estimate represents the additional rate of change in neurocognitive outcome contributed by the mean radiation dose in points/per Gy/per year. It is calculated according to the difference of radiation dose deviated from the population average. 